\title{
СРАВНИТЕЛЬНЫЙ АНАЛИЗ В СОЦИОКУЛЬТУРНОМ РЕГИОНОВЕДЕНИИ
}

\begin{abstract}
Аннотация. Сравнительный анализ как метод научного исследования широко и эффективно используется во многих гуманитарных и естественных науках. Социокультурное регионоведение не является исключением, поскольку применение данного метода позволяет не только выявить закономерности и индивидуальные особенности развития региона, спрогнозировать возможные последствия тех или иных явлений и процессов, но и проследить, как одни и те же социокультурные факторы (процессы) трансформируются под влиянием специфики региона. В статье рассматриваются цели применения компаративистики в научном исследовании, показаны междисциплинарные основы социокультурного регионоведения, определены основные принципы и последовательные этапы применения сравнительного анализа в регионоведческих исследованиях. Примером использования метода сравнительного анализа в социокультурном регионоведении может служить проведенное в статье сопоставление восприятия понятия «отечество» в русской и английской культурах XVIII в. Именно это понятие занимает одно из основных мест в ментальности любой нации, входящего в число важнейших инструментов самоидентификации, интегрирующего личность и социум. Без реконструкции смысла, содержания и эволюции понятия «отечество» невозможно представить себе историю культуры и ментальности любого народа.

Ключевъе слова: культурология, регионоведение, социокультурное регионоведение, социокультурные исследования, методы исследования, междисциплинарность, сравнительный анализ, компаративистика, методология, преподавание.
\end{abstract}

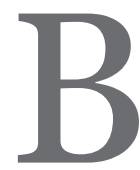

о второй половине XX столетия отчетливо проявилась тенденция интеграции научного знания, что нашло конкретное отражение во взаимодействии разнообразных научных дисциплин, приведшем к появлению новых междисциплинарных областей научного знания, таких как, например, политология, культурология, социокультурная лингвистика, регионоведение и др. Это привело, с одной стороны, к умножению, с другой стороны, к кристаллизации в рамках одной научной дисциплины различных направлений и специализаций. В качестве примера можно использовать социокультурное регионоведение, закономерный результат развития регионоведения как научной дисциплины.

Традиционно под регионоведением понимается область научных знаний, комплексная дисциплина, исследующая регион с точки зрения особенностей его экономики, географии, природы, демографии, политики. В сферу же внимания социокультурного регионоведения, помимо этого и прежде всего, попадает жизнедеятельность населения. Как отмечала
А.В. Павловская, в центре внимания социокультурного регионоведения находятся «люди, население той или иной страны; человеческий фактор рассматривается как главное в существовании любого общественно-политического или историко-культурного региона (в отличие от географического или природного)» ${ }^{1}$. Исследование региона производится посредством изучения в первую очередь истории, культуры и языка, распространенных на данной территории. По мнению исследователей, это позволяет «раскрыть национальные особенности региона во всем его многообразии, определить своеобразие быта и уклада жизни, вскрыть основные факторы, повлиявшие на его развитие, в конечном счете, дает возможность ... анализировать конкретные современные ситуации и прогнозировать будущее»².

\footnotetext{
1 Павловская А.В. Специальность «регионоведение» на факультете иностранных языков и регионоведения МГУ им. М.В. Ломоносова: итоги и перспективы // Актуальные вопросы регионоведения. Вып. II. М., 2007. С. 8.

2 Там же.
} 
Одной из важных задач, связанных с внедрением социокультурного регионоведения в систему научных знаний, является разработка теоретических основ этого научного направления, в том числе, методологических и методических приемов работы. Метод сравнительного анализа, действующий в рамках цивилизационного и системного подходов к познанию, представляется крайне продуктивным и значимым. Компаративистика стала в современной методологии одним из наиболее динамично развивающихся направлений, ее разработка и применение представляется эффективной и открывает перспективы для более полного понимания содержания социокультурного регионоведения.

Сравнение является одним из основных приемов познания внешнего мира. В научной литературе основные приемы компаративистики представлены в настоящее время достаточно широко ${ }^{3}$. Согласно принятым определениям, сравнение это логическая процедура, являющаяся базой всех познавательных действий. Впервые сталкиваясь с незнакомыми предметами, мы оцениваем их, прежде всего, с точки зрения выявления сходств и различий с родственными предметами, а затем выделения в группу. В самом общем смысле сравнение можно определить как отношение тождества и различия, существующее между предметами и явлениями окружающего мира. Без сравнения невозможна оценка не только простейших, но и самых сложных явлений как природы, так и общества. Именно поэтому сравнительный метод стал методологической основой проведения многих научных исследований и в технической сфере, и в гуманитарных науках.

При изучении применения методов сравнительного анализа в социокультурном регионоведении представляется важным проанализировать цели применения компаративистики в научных дисциплинах, формирующих предмет социокультурное регионоведение. Кроме того, необходимо определить виды и принципы проведения сравнительного исследования в социокультурном регионоведении, а также оценить эффективность использования сравнительного метода в социо-

\footnotetext{
3 Cм., напр.: Holt R., Turner J. The methodology of comparative research. N.Y., 1970; Przeworski A., Teune H. The logic of comparative social inquiry. N.Y., 1970; Ковальченко И.Д. Методы исторического исследования. М., 1987; Рэгин Ч. Особенности компаративистики // Современная сравнительная политология. М., 1997; Пивовар Е.И. Теоретические проблемы исторических исследований. М., 2002. Вып. 4.
}

культурном регионоведении, опираясь на опыт конкретно-научного исследования.

Социокультурное регионоведение, как и регионоведение в целом, является междисциплинарной отраслью знания. Изучение региона во всем его многообразии складывается из многих составляющих. Здесь и история, и экономика, и география, и многое другое. Успех исследования зависит во многом от того, насколько полно применяется компаративный метод ко всем отраслям знания, необходимых для научного освоения региона в социокультурном отношении. Однако если методика и техника компаративистики в различных областях знания совпадают, то цели преследуется разные, что можно проиллюстрировать на конкретных примерах.

Сравнительный анализ в лингвистике имеет ряд особенностей. Сравнительно-историческое языкознание - наука, занимающаяся сравнением языков с точки зрения установления из родства, генетической классификации и реконструкции праязыковых состояний. На основе применения сравнительно-исторического метода, изучения типов встречающихся языковых явлений и определения родства языков лингвисты, подобно биологам, классифицируют виды языков. Результаты данных исследований являются бесценными не только для лингвистики как таковой, но и для истории, археологии, этнографии, культурологии и социологии. В конечном итоге они позволяют установить языковую картину мира далеких дописьменных эпох ${ }^{4}$.

Родственная общность языков, вытекающая из их происхождения, предполагает изучение языкаосновы (или группового языка). На основе кропотливого исторически и культурно обусловленного сравнительного анализа, с учетом использования сложных методов, в том числе и математических, ученые получают возможность частично восстанавливать утраченные языки, получать основные данные грамматики, фонетики, лексики. В свое время такие исследования дали блестящие результаты, например, при изучении хеттского языка 5 .

Сравнительно-историческое литературоведение изучает сходство и различие литературно-художественных явлений в разных регионах, обусловленных параллелями в социокультурном

\footnotetext{
${ }^{4}$ Бурлак С.А., Старостин С.А. Введение в лингвистическую компаративистику. М., 2001. С. 4-5.

${ }^{5}$ Реформаторский А.А. Введение в языковедение. М., 1996. C. 212-215.
} 


\section{Философия и культура 4(64) • 2013}

развитии населяющих их народов и взаимовлияниями. На основе выявления степени внешнего воздействия на литературу можно делать выводы о взаимодействии и взаимопроникновении культур, популярности определенных жанров и стилей в литературе, творчестве отдельных писателей, существовании схожих архетипов в различных культурах, например, на основе данных сравнительной мифологии 6 .

Сравнительно-географические исследования используют в своей практике метод географических аналогий, когда данные о каком-либо объекте (геосистеме) выводятся из уже сложившихся знаний о другом сходном объекте или регионе, определяющим в данном случае будет сходство исходных предпосылок, а результатом проведенных исследовании - прогнозирование перспектив развития региона7.

В исторической компаративистике использование взятого за основу тезиса о единой сущности эволюционных исторических процессов позволяет специалистам их анализировать, делая выводы об общем и особенном, региональном и локальном ${ }^{8}$. Основное значение сравнительного метода заключается «в познании исторической реальности через изучение подобий и различий между фактами, относящимися к более, чем одной исторической системе» ${ }^{9}$. Следует особо отметить роль, которая отводится количественным методам в сравнительных исторических исследованиях ${ }^{10}$.

Сравнительная политология - часть сложной и методологически диверсифицированной научной дисциплины - политологии, которая, в свою очередь, стала результатом слияния в начале XX столетия в единое целое двух отраслей знаний: философии и права. Сравнительная политология заняла свое достойное место в ряду политических

${ }^{6}$ См., напр.: Ващенко А.В. Сравнительная мифология. Ч. 1-2. Проект «Академия», 2011 // http://www.tvkultura.ru/ issue.html?id=114088; Жирмунский В.М. Средневековая литература как предмет сравнительного литературоведения // Известия АН СССР. Отделение литературы и языка. М., 1971. Т. ХХХ. Вып. 3. С. 185-197; Неупокоева И.Г. Проблемы взаимодействия современных литератур. М., 1963.

7 Иванова М.В., Штанько М.А. Введение в регионоведение. Методы регионоведческих исследований. Томск, 2007. С. 33.

8 Об этом подробнее см.: Селунская Н.Б. Проблемы методологии истории. М., 2003.

9 Мелконян Э.Л. Проблемы сравнительного метода в историческом знании. Ереван, 1981. С. 49

${ }_{10}$ Карагодин А.В., Петрова О.С., Селунская Н.Б. Количественные методы в исторических исследованиях. М., 2012. наук, а не стала лишь отдельным методом ведения исследования ${ }^{11}$. Политологи видят свою задачу в том, «чтобы описывать властные структуры и социальный контекст их функционирования, а также выявлять действующие здесь закономерности... В связи с этим современная политическая наука избегает каких-либо конкретных оценок. Вопрос, что лучше - демократия или «сильная власть», а если демократия, то какая, - не для компаративиста, а для философа» ${ }^{12}$. Интересно отметить, что именно политологами активно обсуждается проблема правомерности сравнения уникальных по своей сущности обществ. Особый интерес в этом плане представляет статья А. Макинтайра «Возможна ли сравнительная политология?», материалы которой дают отрицательный ответ на поставленный вопрос. Автор сделал вывод о том, что политические общества настолько уникальны, что попытка сравнения приводит к упрощению реальности, как следствие - к искажению результата анализа ${ }^{13}$.

Компаративная социология, наряду с политологией и историей, использует для своих целей сравнительный метод анализа. Кроме того, социологическое исследование, проведенное в форме соцопроса, экспертного опроса, контент-анализа или социологического наблюдения по своей сути компаративно, так как подразумевает проведение обработки данный на основе их соотнесения друг с другом, причем не только в качественном отношении, но и в количественном. По мнению Н.Дж. Спелзера, в социологии, как и в других общественных науках «трудно представить себе анализ, который бы не был сравнительным», «вся социальная наука строится на различиях между людыми и социальными укладами» ${ }^{14}$.

Из приведенных выше примеров отчетливо видно, что уместна и допустима классификация по признаку диахроничности и синхроничности проводимого анализа, по степени субъективизма при проведении исследования, и по возможности применения количественных методов в исследовании. Важными условиями для достижения объективного

11 См.: Ильин М.В. Сравнительная политология: научная компаративистика в системе научного знания // Полис. 2001. № 4; Зазнаев О.И. Основы сравнительной политологии. Казань, 2009.

12 Голосов Г.В. Сравнительная политология. СПб., 2001. С. 339.

${ }_{13}$ MacIntyre A. Is a Science of Comparative Politics Possible? // Philosophy, Politics, and Society. Oxford, 1972.

14 Смелзер Н.Дж. О компаративном анализе, междисциплинарности и интернационализации в социологии // Социс. 2004. № 11. C. $2-3$. 
результата при проведение научного исследования с использованием сравнительного метода является использование системного подхода к анализу информации, использованию достоверной источниковой базы, современных информационных технологий обработки данных. На основепроведения обобщений, аналогий, дедуктивных, индуктивных и традуктивных умозаключений сравнительный метод позволяет расширить горизонты научных знаний.

Сравнительный метод в социокультурном регионоведении имеет широкие возможности и перспективы. Даже первое знакомство с регионом бессознательно начинается с сопоставления. Попадая в чужую страну, каждый путешественник невольно начинает сравнивать ее культуру, образ жизни жителей, социальное и политическое устройство, словом, все то, что служит наполнением понятия «регион», с уже знакомыми ему реалиями. Например, английский первооткрыватель морского пути из Англии на Север России Ричард Чанселлор (Richard Chancellor) в XVI в. в письме к дяде сравнивает архитектуру Лондона и Москвы, царские шатры королей Англии и Франции и Ивана $\mathrm{IV}^{15}$. Русский историк и литератор Н.М. Карамзин в знаменитых «Письмах русского путешественника» (XVIII в.) среди прочего анализирует национальные характеры англичан, французов и итальянцев ${ }^{16}$. Описывая систему высшего и среднего образования в Японии, журналист-международник В.В. Овчинников в книге «Ветка сакуры» (XX в.) проводит аналогии с Россией, справедливо констатируя, что «Япония располагает после России наиболее эффективной и массовой системой народного просвещения» ${ }^{17}$. Отметим, что подобного рода наблюдения могут служить толчком к собственно научному анализу, а не являются таковыми по сути.

Каковы цели и задачи сопоставления, что и как допустимо сравнивать в социокультурном регионоведении? Прежде всего, необходимо определить объекты сравнения. Очевидно, что данные объекты должны быть сопоставимыми по сути. Во-первых, мы можем попытаться сравнить регион с регионом ${ }^{18}$. Во-вторых, сравнения могут

\footnotetext{
15 Письмо Ричарда Чанселлора к своему дяде Кристоферу Фронтингему. 1554. Архангельск, 1998. С. 38, 50.

16 Карамзин Н.М. Письма русского путешественника. Л., 1984. C. 384.

17 Овчинников В.В. Сакура и Дуб. М., 2005. С. 160.

18 Под регионом в данном контексте понимаем страну, например, Великобританию и Россию.
}

проводиться внутри одного, отдельно взятого региона, например, в регионе Российская Федерация - могут сравниваться Среднее Поволжье и Смоленская область.

Сравнительный анализ в социокультурном регионоведении предполагает соблюдение ряда принципов. Подчеркнем, что без четко определенных хронологических рамок невозможно даже элементарное географическое определение понятия «регион». Невозможно представить себе сопоставление регионов как отдельных единиц вне исторического контекста. Так, говоря о разных этапах истории России XX-XXI вв., мы помним о том, что исторические события разворачиваются не только во времени, но и в пространстве, следовательно, анализироваться должны разные географические единицы. Что уж говорить о таких концептах, как культурные ценности, национальное самосознание и т.п. Поэтому сопоставление регион / регион может происходить только на синхронном уровне. Исследователи подчеркивают, что необходимо говорить о «сопоставительном регионоведении на синхронном срезе» ${ }^{19}$.

Отметим и другой обязательный принцип, который требует соблюдения при проведении сравнительного анализа в социокультурном регионоведении. Речь идет о том, что нельзя пытаться «объять необъятное», невозможно оценить все и сразу. Необходимы четкая классификация, подразделение и ранжирование объектов исследования в рамках компаративного анализа. Сравнение необходимо проводить строго в соответствии с выбранными параметрами, совокупность которых определяет константу региона, например, языковой, религиозный, этнический, социокультурный параметры. Другой возможный вариант действий изучение составляющих выбранных параметров, анализ значимых понятий и явлений, образов, роли персоналий и др.

При проведении сравнительного анализа в социокультурном регионоведении следует учитывать, что ни один регион не является абсолютно однородным по своему наполнению. Можно рассматривать соседство внутри региона различных культур, что проявляется в различии языков, религий, укладов жизни, особенностей бытования. Таким образом, внутри одного региона сравнение должно проводиться с учетом названных выше двух условий. Так, изучая Великобританию, мы

\footnotetext{
19 Елистратов В.С. Регионоведение. Ищите термин // Актуальные проблемы регионоведения. Вып. І. М., 2004. С. 74.
} 


\section{Философия и культура 4(64) • 2013}

должны учитывать культурные особенности не только англичан, но и валлийцев, шотландцев, ирландцев, кроме того, сравнения возможны в рамках схемы «центр - периферия».

Проведение исследования с применением сравнительного анализа в социокультурном регионоведении предполагает выполнение нескольких этапов. Важным является формулировка целей исследования, постановка исследовательской задачи. Как писал И.Д. Ковальченко, «правильная постановка исследовательской задачи при любых... методах ее решения в первую очередь требует всестороннего подхода к изучаемым объектам, явлениям и процессам..., рассмотрения их во всем многообразии, внутренней сложности и противоречивости, взаимосвязи и обусловленности, в развитии ${ }^{20}$. Только целостный подход к объекту регионоведческого исследования является правомерным.

Также необходимо обоснованно подходить к выделению объектов сравнения, должны быть обозначены вопросы целесообразности сравнения регионов, однородности объектов и их сопоставимости. Кроме того, необходимо установление репрезентативности данных, а затем определение критериев, параметров сравнения, то есть характеристик, по которым будет проводиться анализ.

В современных социокультурных регионоведческих исследованиях предпочтительным представляется создание информационной базы исследования на основе аккумулированных и классифицированных данных. Следующими этапами являются проведения сравнительного анализа с целью выявление сходств и различий изучаемых регионов, определение причин несоответствий, при наличии необходимых данных - прогнозирование перспектив развития и подведение итогов исследования.

Приведем конкретный пример применения сравнительного анализа в социокультурном регионоведении. С целью изучения и сопоставления менталитетов двух стран была поставлена задача анализа значимого понятия «отечество», занимающего одно из основных мест в ментальности любой нации, входящего в число важнейших инструментов самоидентификации, интегрирующего личность и социум. Без реконструкции смысла, содержания и эволюции понятия «отечество» не-

\footnotetext{
${ }^{20}$ Ковальченко И.Д., Тишков В.А. Итоги и перспективы применения количественных методов в советской и американской историографии // Количественные методы в советской и американской историографии. М., 1983. С. 15.
}

возможно представить себе историю культуры и ментальности любого народа ${ }^{21}$. Хронологические рамки исследования ограничены XVIII в., исследуемые регионы - Россия и Британия. Выбор хронологических рамок правомерен и целесообразен, поскольку как Россия на рубеже XVII-XVIII вв., так и Британии несколькими десятилетиями вступили в период Нового времени, обе страны переживали процессы формирования наций и империй, бурный промышленный рост, развитие науки и образования. Именно это столетие сформировало ту национальную картину мира и ту систему ценностей, которые будут развиваться в последующие века и сохранят актуальность вплоть до наших дней. Российская и английская культуры развивались в сходном направлении модернизации и рационализации всех сторон жизни общества, социального и законодательного реформирования.

Параметрами сравнения данного социокультурного регионоведческого исследования выступали этимология понятия «отечество» в культурах России и Британии, конкретно-речевое употребление понятия в исследуемый исторический период, особенности патриотизма россиян и британцев в XVIII в.

Информационная база исследования создана на основе анализа значительного количества законодательных документов, публицистических материалов, художественной и мемуарной литературы, исследовательской литературы с точки зрения соотнесения предлагаемой в ней информации с темой исследования.

Сравнительный анализ этимологии понятия «отечество» в России и Британии, конкретно-речевого использования на различных этапах изучаемого периода показал, что для России XVIII в. понятие «отечество» - стержневое, но идущее как бы сверху вниз, от государства к индивиду. Для российских реалий вектор личностных интересов ориентирован, прежде всего, на общественное созидание, в результате чего идея служения Отечеству, как наивысшее проявление гражданского долга, становится основным ценностным ориентиром эпохи. В английской же картине мира наоборот: Отечество создается, ментально и политически моделируется индивидом, служит ему. Государство находится на службе у человека, а не наоборот. Британское общество - индивидуалистское по своей сути, в то

\footnotetext{
21 См. об этом: Смирнова Г.Е. Понятие «отечество» в английской и русской культурах XVIII века. Дисс. на соиск. уч. ст. канд. культурологии. М., 2003.
} 
время как россияне склонны к патернализму, что характерно как для XVIII в., так и для современной ситуации. Таким образом, результатом социокультурного исследования регионов в представленном аспекте, стали выводы, обогатившие знания об особенностях ментальности жителей регионов Россия и Британия, картинах мира, сформированных в далеком XVIII в., но четко просматривающимся и в наши дни.

Приведенный пример хоть и является частным, однако наглядно подтверждает мысль о том, что сравнительный метод эффективен для приложения к научным исследования в области социокультурного регионоведения. При помощи сравнительного анализа можно не только изучить прошлое региона, но и оценить современное состояние, и заглянуть в будущее.

Актуальным представляется опыт практического применение метода сравнительного анализа в повседневной практике преподавания регионоведения в высшей школе. В качестве примера может быть использован опыт факультета иностранных языков и регионоведения МГУ имени М.В. Ломоносова, в частности, преподавание дисциплины «Сравнительное регионоведение» на отделении региональных исследований. Также в программе данного отделения имеется ряд дисциплин, неотъемлемой частью которых стали темы, напрямую связанные со сравнительным регионоведением. Среди них назовем курсы, включенные в профессиональный блок ФГОС ВПО направления подготовки «Регионоведение» - «Русский мир в контексте мировых цивилизаций», «Регион и мир», «Регионоведение», а также целый ряд специальных курсов, посвященных культурным связям между различными регионами, среди них отметим «Русско-французские культурные связи» «Русско-итальянские культурные связи», «Русско-британские культурные взаимосвязи», «"From me to you": Россия и Англия в XX-XXI веках», «Австралия: история развития страны. Культурно-лингвистические связи Великобритании и Австралии» ${ }^{22}$ и др.

Нельзя обойти стороной дисциплины, связанные с преподаванием иностранных языков. Причем это не только социолингвистический лекционный курс «Regional Varieties of English: Language through Culture (British English, American English, Australian English, Canadian English)», сама суть которого состоит в анализе «различий современного английского языка в представленных странах с учетом исторического и культурного фона англоязычных наций» 23 , но и дисциплины, связанные со всеми аспектами перевода, ибо грамотный перевод невозможен без проведения аналогий не только лингвистических, но и культурологических ${ }^{24}$. Наиболее яркой иллюстрацией прикладного использования сравнительного социокультурного регионоведения может служить тематика дипломных работ, выполненных студентами факультета за последние годы.

Использование сравнительного метода в научных исследованиях является залогом успешного освоения новых горизонтов знаний, дает платформу для проведения научных исследований и, что очень важно, является базой для плодотворного образовательного процесса.

\section{Список литературъц:}

1. Бурлак С.А., Старостин С.А. Введение в лингвистическую компаративистику. М., 2001.

2. Голосов Г.В. Сравнительная политология. СПб, 2001.

3. Елистратов В.С. Регионоведение. Ищите термин // Актуальные проблемы регионоведения. Вып. I. M., 2004.

4. Жирмунский В.М. Средневековая литература как предмет сравнительного литературоведения // Известия АН СССР. Отделение литературы и языка. М., 1971. Т. ХХХ. Вып. 3. С. 185-197.

5. Иванова М.В., Штанько М.А. Введение в регионоведение. Методы регионоведческих исследований. Томск, 2007.

\footnotetext{
22 Учебные программы. Специальность «регионоведение» (350300). Ч. 1. Общегуманитарные и общепрофессиональные дисциплины. М., 2007; Ч. 2. Дисциплины специализации. М., 2007.

23 Там же. Ч. 2.

${ }^{24}$ Об этом см.: Павловская А.В. Специальность «регионоведение» на факультете иностранных языков и регионоведения МГУ им. М.В Ломоносова: итоги и перспективы // Актуальные вопросы регионоведения. Вып. ІІ. М., 2007.
} 


\section{Философия и культура 4(64) • 2013}

6. Ковальченко И.Д. Методы исторических исследований. М., 1987.

7. Ковальченко И.Д., Тишков В.А. Итоги и перспективы применения количественных методов в советской и американской историографии // Количественные методы в советской и американской историографии. М., 1983.

8. Неупокоева И.Г. Проблемы взаимодействия современных литератур. М., 1963.

9. Павловская А.В. Специальность «регионоведение» на факультете иностранных языков и регионоведения МгУ им. М.В Ломоносова: итоги и перспективы // Актуальные вопросы регионоведения.

Вып. II. М., 2007.

10. Пивовар Е.И. Теоретические проблемы исторических исследований. Вып. 4. М., 2002.

11. Рэгин Ч. Особенности компаративистики // Современная сравнительная политология. М., 1997.

12. Селунская Н.Б. Проблемы методологии истории. М., 2003.

13. Смирнова Г.Е. Понятие «отечество» в английской и русской культурах XVIII века: дисс. на соиск. уч. ст. ... канд. культурологии. М., 2003.

14. Holt R., Turner J. The methodology of comparative research. N.Y., 1970.

15. Przeworski A., Teune H. The logic of comparative social inquiry. N.Y., 1970.

\section{References (transliteration):}

1. Burlak S.A., Starostin S.A. Vvedenie v lingvisticheskuyu komparativistiku. M., 2001.

2. Golosov G.V. Sravnitel'naya politologiya. SPb, 2001.

3. Elistratov V.S. Regionovedenie. Ishchite termin // Aktual'nye problemy regionovedeniya. Vyp. I. M., 2004.

4. Zhirmunskiy V.M. Srednevekovaya literatura kak predmet sravnitel'nogo literaturovedeniya // Izvestiya AN SSSR. Otdelenie literatury i yazyka. M., 1971. T. XXX. Vyp. 3. S. 185-197.

5. Ivanova M.V., Shtan'ko M.A. Vvedenie v regionovedenie. Metody regionovedcheskikh issledovaniy. Tomsk, 2007.

6. Koval'chenko I.D. Metody istoricheskikh issledovaniy. M., 1987.

7. Koval'chenko I.D., Tishkov V.A. Itogi i perspektivy primeneniya kolichestvennykh metodov v sovetskoy i amerikanskoy istoriografii // Kolichestvennye metody v sovetskoy i amerikanskoy istoriografii. M., 1983.

8. Neupokoeva I.G. Problemy vzaimodeystviya sovremennykh literatur. M., 1963.

9. Pavlovskaya A.V. Spetsial'nost' «regionovedenie» na fakul'tete inostrannykh yazykov i regionovedeniya MGU im. M.V Lomonosova: itogi i perspektivy // Aktual'nye voprosy regionovedeniya. Vyp. II. M., 2007.

10. Pivovar E.I. Teoreticheskie problemy istoricheskikh issledovaniy. Vyp. 4. M., 2002.

11. Regin Ch. Osobennosti komparativistiki // Sovremennaya sravnitel'naya politologiya. M., 1997.

12. Selunskaya N.B. Problemy metodologii istorii. M., 2003.

13. Smirnova G.E. Ponyatie «otechestvo» v angliyskoy i russkoy kul'turakh XVIII veka. Diss. na soisk. uch. st. kand. kul'turologii. M., 2003.

14. Holt R., Turner J. The methodology of comparative research. N.Y., 1970.

15. Przeworski A., Teune N. The logic of comparative social inquiry. N.Y., 1970. 